\title{
A LÍNGUA POMERANA EM PERCURSO HISTÓRICO BRASILEIRO: UMA VARIEDADE (NEO)AUTÓCTONE
}

\author{
POMERANIAN LANGUAGE IN A BRAZILIAN HISTORICAL COURSE: \\ A (NEO) AUTOCHTHONOUS VARIETY \\ Mônica Maria Guimarães Savedra | Lattes | msavedra@id.uff.br \\ Universidade Federal Fluminense $\mid \mathrm{CNPq}$
}

Leticia Mazzelli-Rodrigues | Lattes | 1mazzelli@id.uff.br

Universidade Federal Fluminense

Resumo: Este trabalho tem por objetivo propor o estudo da língua pomerana falada no Espírito Santo como uma variedade (neo)autóctone brasileira, a partir da sua vitalidade linguística e do seu uso contínuo durante o longo período de tempo na região. A discussão se desenvolve a partir das perspectivas histórica e linguística, relacionando conceitos referentes à língua de imigração, territorialidade e autoctonia. Partimos dos estudos de Tacke (2015) e Zenker (2011) para propor o reconhecimento da autoctonia desta língua de imigração e delimitamos o estudo ao Município de Santa Maria de Jetibá, reconhecido como o mais pomerano do Estado. Inicialmente apresentamos uma ambientação sóciohistórica do Brasil à época da imigração e em seguida discorremos sobre o uso atual da língua pomerana no locus selecionado para o estudo. Finalmente, com base no suporte teórico selecionado, propomos a definição de língua (neo)autóctone brasileira para a variedade pomerana em questão.

Palavras-chave: Língua Pomerana; Autoctonia; Língua de imigração; Territorialidade.

Abstract: This paper approaches the Pomeranian language spoken in Espírito Santo as a (neo)autochthonous Brazilian variety, based on its linguistic vitality and continuous use overtime in the region. The discussion develops from the historical and linguistic perspectives, relating concepts related to the language of immigration, territoriality and autochthony. From the studies of Tacke (2015) and Zenker (2011), we propose the recognition of the autochthonousness of this language of immigration and delimit the 
study to the municipality of Santa Maria de Jetibá, recognized as the most Pomeranian of the state. Initially, we present a socio-historical context of Brazil at the time of immigration and then we discuss the current use of the Pomeranian language in the locus selected for the study. Finally, based on the theoretical support selected, we propose the definition of Brazilian (neo)autochthonous language for the Pomeranian variety in question.

Keywords: Pomeranian Language; Autochthony; Language ofimmigration; Territoriality.

\section{Introdução}

Neste estudo analisamos, com base em perspectivas históricas e linguísticas, a presença da língua pomerana no Município de Santa Maria de Jetibá (SMJ). Para propor o conceito de autoctonia, recorremos aos estudos antropológicos de Zenker (2011) e linguísticos de Tacke (2015) que ao analisarem diferentes situações de contato, cada um na perspectiva de sua área, relacionam o grau de vitalidade das línguas, o seu uso e o tempo em que as mesmas estão presentes em determinado território.

Procuramos aqui mostrar como os conceitos relativos à territorialidade e língua se inter-relacionam, a fim de legitimar a classificação de (neo) autóctone proposta. Para tanto, traçamos uma análise histórica, a fim de observar o tempo e o grau de vitalidade da língua pomerana no Município de SMJ. A escolha desse município justifica-se como objeto de análise, pois é reconhecido como o mais pomerano do Estado, assim como apontado na própria homepage da Prefeitura Municipal de Santa Maria de Jetibá (2016a).

$\mathrm{O}$ artigo está estruturado em três partes. Inicialmente realizamos um breve levantamento acerca do contexto sócio-histórico do Brasil e da Pomerânia, país da origem à época da imigração (1859). Em seguida, apresentamos o atual contexto da língua pomerana no município, a partir de estudos realizados na última década (BREMENKAMP, 2014; SAVEDRA \& HÖHMANN, 2013; HÖHMANN, 2011). Finalmente, a partir da relação entre língua, tempo e território, propomos a definição de língua (neo) autóctone brasileira para a variedade pomerana falada no município de SMJ no Espírito Santo.

\section{Contexto sócio-histórico do Brasil e a chegada dos imigrantes pomeranos no}

\section{Espírito Santo}

Como apontado em estudos históricos realizados por Lesser (2015) e Skidmore (1997), o fim cada vez mais evidente da escravidão na segunda metade do século XIX induz busca por saídas para a problemática de mão de obra, que seria então ocasionada. 
Manifestações de mudança econômica e a ideia do "branqueamento" da população brasileira faziam parte do discurso das elites intelectuais e políticas, que viam na imigração a solução para os problemas do país.

O contexto histórico-social do Brasil à época foi marcado pelo desejo de mudança, favorecendo o discurso relacionado às políticas de imigração: "intelectuais, políticos, assim como lideranças culturais e econômicas viam [...] os imigrantes como agentes do aperfeiçoamento de uma nação imperfeita” (LESSER, 2015, p. 28). Grande parte das elites intelectuais e políticas brasileiras era favorável ao uso de imigrantes como força de trabalho, “trazendo além da mão-de-obra, o ‘branqueamento' racial à população brasileira” (SKIDMORE, 1997, p. 9).

Como ressaltado por Bahia (2011) e Martinuzzo (2009), o cenário europeu no século XIX era de fome e miséria. Em busca de melhores condições de vida e com a expectativa de casa e trabalho, inúmeros imigrantes provenientes da Europa receberam promessas de incentivos do governo brasileiro para se estabelecerem e se estabilizarem. Entretanto, Seyferth (2002) ressalva que havia critérios a serem seguidos que estavam vinculados à legislação migratória, relacionados à categoria de admissão de estrangeiros. O imigrante ideal para a política imigratória brasileira do século XIX era o da qualidade de colono: "Nas regras de admissão de estrangeiros o imigrante ideal, o único merecedor de subsídios, é o agricultor; mais do que isso, um agricultor branco que emigra em família” (SEYFERTH, 2002, p. 119). O objetivo do governo brasileiro era, portanto, privilegiar famílias de imigrantes para que trabalhassem no campo e povoassem territórios vazios. Isso pode ser observado na Figura 1, que retrata a primeira página do contrato de um colono pomerano em 1859 com o governo brasileiro, em versão português-alemão. 
Figura 1. Contrato de colono pomerano com o governo brasileiro

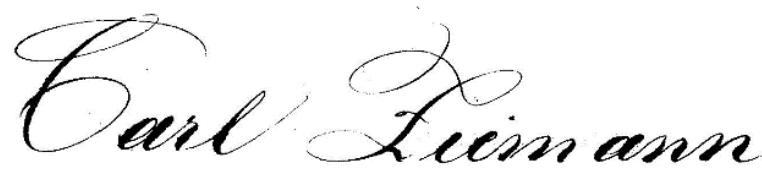

\section{oㅡ}

A Associaçå Central de Colonisaçăo no phio de Eaneiro, por intermedio do seu Agente Geral o Dor F. Schmidt em Hamburgo, contrata com o Colono abaixo nomeado debaixo das condições seguintes:

Art. 1. ${ }^{0}$ A Associą̧ão Central de Colonisação no Rio de Janeiro, devidamente autorisada pelo Governo de Sua DIagestade 6 Tmperador do Fratail, e debaixo da sua responsabilidade, obriga-se:

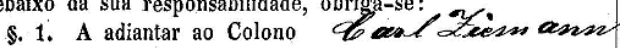

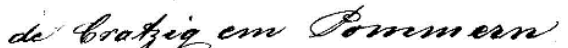

e sua familia, composta de 4 pessôas, as passagens dè:Hamburgo até o Rio de Jańtir o, pagando pelos maịores - de 10 annos para cima 80 e pelos menờes dè 3 até 10 annos $\psi \mathcal{O}$. thalers da Prussia; e nada pagarão os mènores até 3 annos.

\$. 2. A deduzir da importancia das passagens a subvençấo do Gôverno Imperial de $37 \$ 500$ Reis 'por Colono adulto de 10 até 45 annos, e de $22 \$ 500$. Reis por menor dè 5 até 10 annos.

\$. 3. A pagar as despezas que os Colonos fizerem na huspedàtia da Associação em quanto não partirem para o seu 'əstino, não sendo estas despezas carregadas em divida.

\$. 4. A dar-lhes passagem gratuita até a colonia de Leopoldenal na Provincia de bifusito fanto.

e ahi

fornecer- thes tambem gratuitamente alojamento provisorio.

S. 5. A pòr á disposição de cada chefe de familia um lote de terras contendo 120,000 braças quadradas on metade d'esśa arèa à escolha do colono conforme as suas forças. Esse lote de terras será entregue medido e detnarcado e com uma derrubada e queimada em extensão de 10,000 braças quadradas pouco mais ou menos.

\$. 6. A fazer o suprimento de viveres por adiantamento até seis mezes, de ferramentas de lavoura, sementes de milho, feijão, arroz e algumas outras, bem como batatas e mandioca para as primeiras plantações, se o colono d'sto carecer no começo de seus trabalhos.

\$. 7. A proporcionar ao Colono os serviços que houver na Colonia, se quizer trabalhar á jornal, o qual será arbitrado entre 1000 e 1200 reis a secco, segundo os costumes no lugar. N'este caso cessará o adiantamento de sustento.

\$. 8. As terras serão vendidas a prazo e na razão de 11 real a braça quadrada, entrando n'este preço as derrubadas e mais trabalhos preparatorios acima declarados.

\$. 9. 0 titulo da venda das terras será passado gratuitamente pelo Delegado da Reparticão Geral das Terras publicas иа Provincia de

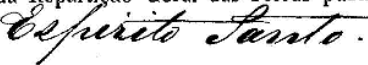

Art $20 \quad 0$ Colono se obriga:

\$. 1. A reembolsar o preço das terras como todos os utros adiantamentos recebidos (passagem, mantimentos, inArumentos \&c.) dentro de cinco annos e em Irez prestaçôe guaes, a contar do fim do segundo anno do estabelecimento

nà colonia. Durante a dito prazo não se contará juros, e indo elle correrá 0 juro de 6 por cento.

\section{No}

Der Eentral : Betein für Eolonifation in Mio De Taneiro bat Durd Bermittlung feines General= 2 ggenten,

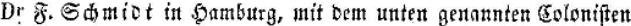
einen Bertrag unter folgenten Bebingungen abgeidjofien:

Frt. 1. Der Central= Berein für đolonifation in $\Re$ iv be

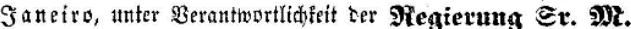

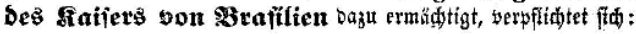

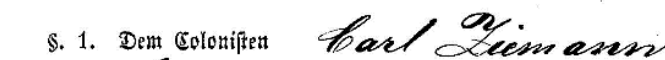

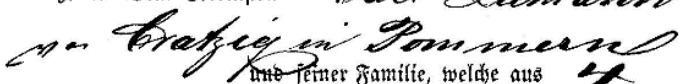

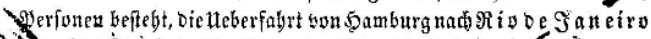

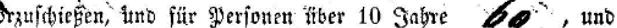

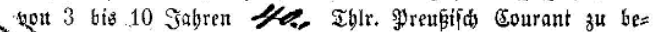

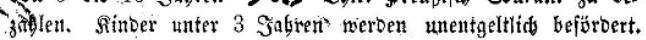

\$. 2. Bon Dem Belaufe Der Ueberfabrt bie Subvention ser

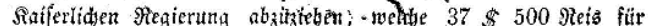
jeben erwadfenen Coloniffen won 10 bis 45 Sabren, und $22 \$$

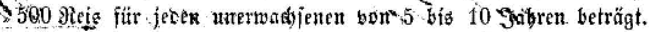

\$. 3. Die Roiten zu bezahlent, welde bie Goloniften in ber

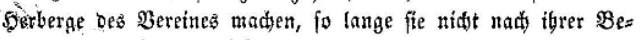
ftimmutg abgegen, Da bieje fiofiten nidjt ale Sdulto belnîtet werDent.

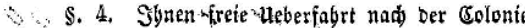

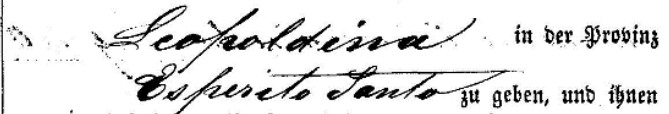

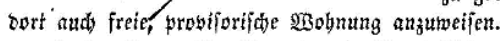

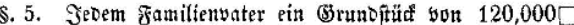

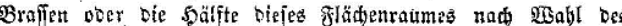
Coloniften uno in Uebereinftimmung mit feinen $\mathscr{H}$ rbeitsłräften zur

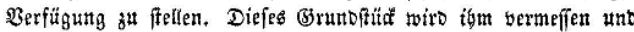

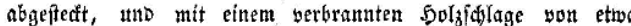
$10,000 \square \mathcal{B}$ riñen übergebert.

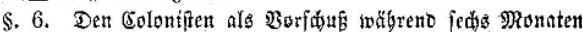

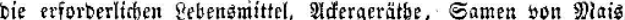

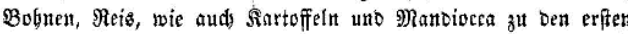
Yyflant nöthig baben.

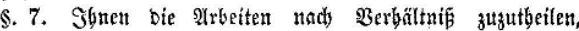
weldte auf ber Colonie vorfonmen, wenn fie int $\mathfrak{T a g}$ glo hn arbeiten

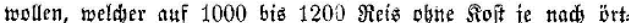

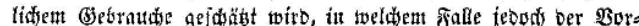

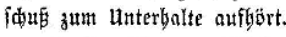

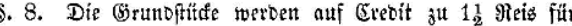

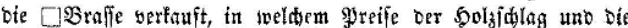
übrigen oben genannten $\mathfrak{B}$ orarbeiten begrififen finto.

\$. 9. Der Berfaufstitel bes Booens twiro Dur Den (Som

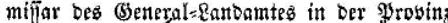

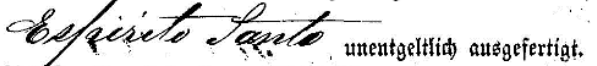

Art.2. Der Colonit werpfitibtet fids:

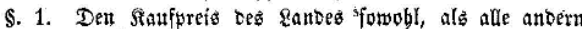

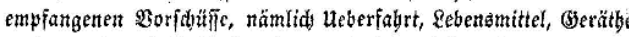
4. f. tw., innerball fünf Sabren und in brei Terminen,

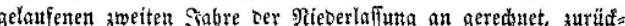

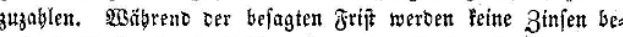
redjet; if fie aber werfitidfen, fo werten $6 \%$ werlangt.

Fonte: Arquivo Público do Estado do Espírito Santo - Arquivo digital (1859-1860). 
Acerca da imigração no Espírito Santo, Rocha (1984 apud HÖHMANN, 2011, p. 19) aponta que houve três fases distintas: a primeira, do ano 1847 a 1881; a segunda, de 1882 a 1887; e a terceira, de 1888 a 1896. Segundo levantamento realizado por Franceschetto (2014), o maior fluxo de imigrantes germânicos ocorreu durante a primeira fase de imigração nas décadas de 1850 até o final da década de 1970. Observa-se, ainda, que de aproximadamente 4.000 imigrantes germânicos, os pomeranos correspondiam a $56 \%$ do total de imigrantes chegados ao Espírito Santo até 1900. Seibel (2016) ressalta que, apesar dos registros históricos brasileiros, não há como precisar em termos exatos quantos pomeranos chegaram ao Brasil, uma vez que esses foram registrados muitas vezes como prussianos e/ou alemães. ${ }^{1}$

De acordo com Rölke (1996), a partir de 1859 os primeiros imigrantes provenientes da Pomerânia chegaram ao Espírito Santo na Colônia de Santa Leopoldina, território hoje pertencente a SMJ ${ }^{2}$. Diferentemente do que lhes fora prometido pelo governo brasileiro, os imigrantes observaram um cenário de dificuldades à sua frente. Terras acidentadas, matas fechadas, falta de assistência médica, dificuldades com a língua portuguesa, além de dívidas com o governo brasileiro, faziam parte da realidade dos pomeranos no Brasil. Segundo Martinuzzo, “a esse povo não restou alternativa que não fosse o fortalecimento comunitário" (MARTINUZZO, 2009, p. 61), fato que favoreceu o isolamento geográfico dessas comunidades em áreas rurais do Espírito Santo.

Estudos linguísticos acerca da imigração pomerana, como os realizados por Tressmann (2005) e Höhmann (2011), apontam que múltiplos fatores contribuíram para a preservação da língua e cultura daquele povo. Tressmann (2005) afirma que o grande número de imigrantes provenientes da Pomerânia tenha sido fator crucial para a preservação da língua. Durante o período de imigração, outros imigrantes também se estabeleceram na colônia de Santa Leopoldina, dentre eles: holandeses, alemães e suíços. O autor afirma que o grupo dos pomeranos era maior em relação a outros grupos de imigrantes, por isso a utilização da língua pomerana era de uso comum entre eles. Höhmann

\footnotetext{
${ }^{1}$ À época da imigração no Brasil, Rölke (1996) aponta que a Pomerânia era uma província da Prússia e mais tarde, em 1871, com a unificação dos estados alemães, passa a fazer parte do Império alemão. Até 1945, a Pomerânia estava dividida entre Pomerânia Ocidental e Pomerânia Oriental. Com a derrota da Alemanha na II Guerra Mundial (1945), a Pomerânia Oriental é anexada à Polônia e a Pomerânia Ocidental passa a integrar o atual Estado de Mecklenburgo-Pomerânia Ocidental, Alemanha. [...] "A partir daquele ano, a Pomerânia como tal desaparece do mapa da Europa” (TRESSMANN, 2008, p.2).

2 Santa Maria de Jetibá foi levado à categoria de município no dia 6 de maio de 1988, ao se desmembrar do Município de Santa Leopoldina através da Lei Estadual n 4.067 (IBGE, 2016).
} 
defende a tese de que o isolamento geográfico e a influência da igreja luterana foram favoráveis à manutenção linguística e cultural dos pomeranos.

A partir dessa contextualização histórica, podemos observar alguns dados acerca da imigração no Espírito Santo, assim como o cenário vivenciado pelos imigrantes ao chegarem ao Brasil. Também foram mencionados alguns fatores que propiciaram a manutenção da língua e costumes pomeranos em comunidades rurais no Espírito Santo.

A seguir, apresentamos informações acerca da situação linguística atual da língua pomerana falada no Espírito Santo, mais precisamente no Município de SMJ e também dados acerca da manutenção dessa língua, símbolo da resistência cultural dos pomeranos.

Como demonstrado por Tressemann (2005), nas comunidades onde os imigrantes pomeranos se estabeleceram, língua e costumes, como rituais e danças, resistem à influência da língua portuguesa, fazendo parte do cotidiano dos descendentes, também reconhecidos como pomeranos.

\section{0 panorama linguístico do pomerano no Espírito Santo}

Classificada na categoria de "língua de imigração" pelo Inventário Nacional de Diversidade Linguística (INDL), a língua pomerana é atualmente um dos elementos de maior representatividade da cultura desse povo. De acordo com publicação do Instituto de Investigação e Desenvolvimento em Política Linguística (IPOL), atualmente, a língua pomerana é cooficializada em cinco municípios do Espírito Santo, e passará a integrar o Inventário das Línguas Brasileiras (IPOL, 2016b). Com as leis de cooficialização e outros projetos, como o Programa de Educação Escolar Pomerana que será discutido mais adiante, observa-se que há atualmente movimentos liderados por pomeranos e pesquisadores em prol da garantia por lei para proteger a língua nas comunidades onde o pomerano se faz presente.

Segundo Foerste (2016), hoje há cerca de 150 mil descendentes de pomeranos no Estado do Espírito Santo, distribuídos em diversos municípios, como "Domingos Martins, Marechal Floriano, Santa Leopoldina, Santa Maria de Jetibá, Santa Teresa, Afonso Cláudio, Brejetuba, Laranja da Terra, Itarana, Itaguaçu, Baixo Guandu, Colatina, Pancas, São Gabriel da Palha, Vila Pavão, Vila Valério, Águia Branca, Vitória, Vila Velha e Serra” (MORELLO, 2015, p. 44).

Alguns estudos recentes foram conduzidos a fim de observar e analisar a situação da língua pomerana no Espírito Santo, como os realizados por Höhmann (2011), Bremenkamp (2014) e Savedra e Höhmann (2013). Os três estudos em questão dis- 
correm sobre a situação da língua pomerana em distintos municípios capixabas, tendo o Município de SMJ como ponto em comum. O município em questão foi escolhido por este trabalho a fim de ilustrar a situação linguística da língua pomerana no Espírito Santo, pois é notoriamente conhecido como o mais pomerano do Espírito Santo.

Localizado a $80 \mathrm{~km}$ da capital Vitória, o Município de SMJ está na região Serrana do Espírito Santo. De acordo com dados do IBGE, a população é de 34.176 habitantes (IBGE, 2010) e teve projeção de 39.396 habitantes em 2016 (IBGE, 2015). Segundo publicação em site da Prefeitura Municipal de Santa Maria de Jetibá (2016b), a região é fortemente marcada pela presença da agricultura, influência cultural do povo pomerano, eminentemente agrícola. A origem histórica do povoamento dessa região e a sobrevivência de traços culturais dos imigrantes permitem observar ainda hoje, em Santa Maria de Jetibá, a língua pomerana sendo comumente utilizada no cotidiano da comunidade.

Em estudo realizado por Höhmann (2011), foram entrevistados 263 pessoas em SMJ e outros municípios ao seu redor a fim de verificar a situação linguística de comunidades falantes do pomerano. A pesquisadora então dividiu seus informantes em gerações, respeitando as seguintes faixas etárias: geração I - de 4 a 29 anos, geração II - de 30 a 49 anos e geração III - de 50 a 72 anos.

Quando perguntados sobre sua primeira língua, 77\% dos entrevistados afirmaram ser o pomerano. Já quando indagados em qual língua preferiam se comunicar, o número dos que escolheram pomerano diminui consideravelmente, pois apenas $44,5 \%$ dos entrevistados escolheram o pomerano. Em relação à frequência de uso da língua, cerca de $80 \%$ dos entrevistados alegaram seu uso cotidiano.

Apesar do frequente uso do pomerano pelos habitantes, a pesquisadora afirma que a língua se encontra em estágio de extinção, classificando-a, na escala fornecida pela UNESCO no documento Language Vitality and Endangerment (2003), como definidamente ameaçada. Höhmann justifica sua classificação, contrastando dados referentes à transmissão geracional da língua, pois houve divergência na resposta das diferentes gerações dos informantes.

Quando perguntados sobre sua competência linguística em português e pomerano, $71 \%$ da geração I classificou como boa sua competência em língua pomerana. Em relação ao português, $78 \%$ consideravam-na boa. Em relação à geração III, a competência linguística do pomerano foi considerada como "boa” por $83 \%$ dos entrevistados. Em contrapartida, somente 33\% dos informantes da geração III classificaram sua competência linguística em português como "boa”. A autora pontua que a geração mais nova está aparentemente perdendo a língua pomerana. 
O panorama linguístico do pomerano também pode ser observado a partir dos estudos de Bremenkamp (2014) acerca da comunidade linguística de Caramuru, em SMJ. A pesquisa de Bremenkamp contou com 40 entrevistas e os seus informantes foram divididos em faixas etárias: de 09 a 13 anos (G-I), de 14 a 30 anos (G-II), de 31 a 55 anos (G-III) e com mais de 55 anos (G-IV). De acordo com Bremenkamp, 72,5\% da comunidade entrevistada é bilíngue pomerano/português e na (G-IV), faixa etária acima dos 55 anos, foi observado que $45,5 \%$ dos entrevistados é monolíngue pomerano. Segundo Bremenkamp, esse resultado "implica que, até relativamente pouco tempo, o contato com o português não era comum ou rotineiro” (BREMENKAMP, 2014, p. 166). Dentre outras perguntas, a pesquisadora também indaga sobre a preferência linguística dos informantes, como mostra a Tabela 1:

Tabela 1. Preferência linguística dos informantes.

\begin{tabular}{|c|c|c|c|c|c|}
\hline $\begin{array}{c}\text { Em que língua } \\
\text { você se sente } \\
\text { melhor? }\end{array}$ & $\begin{array}{c}09-13 \\
\text { anos }\end{array}$ & $\begin{array}{c}14-30 \\
\text { anos }\end{array}$ & $\begin{array}{c}31-55 \\
\text { anos }\end{array}$ & $\begin{array}{l}>55 \\
\text { anos }\end{array}$ & TOTAL \\
\hline \multirow{2}{*}{ Pomerano } & $4 / 11$ & $2 / 10$ & $5 / 8$ & $10 / 11$ & $21 / 40$ \\
\hline & $36,4 \%$ & $20 \%$ & $62,5 \%$ & $90,9 \%$ & $52,5 \%$ \\
\hline \multirow{2}{*}{ Português } & $5 / 11$ & $8 / 10$ & $2 / 8$ & \multirow{2}{*}{0} & $15 / 40$ \\
\hline & $45,5 \%$ & $80 \%$ & $25 \%$ & & $37,5 \%$ \\
\hline Português/ & $2 / 11$ & \multirow{2}{*}{0} & $1 / 8$ & $1 / 11$ & $04 / 40$ \\
\hline Pomerano & $18,1 \%$ & & $12,5 \%$ & $9,1 \%$ & $10 \%$ \\
\hline TOTAL & 11 & 10 & 08 & 11 & 40 \\
\hline
\end{tabular}

Fonte: Bremenkamp (2014, p. 176).

Observa-se que os grupos I e II, respectivamente 09-13 anos e 14-30 anos, preferem o português ao pomerano. Já os grupos III e IV, respectivamente 31-55 anos e acima de 55 anos, preferem o pomerano ao português. Os resultados encontrados por Bremenkamp foram similares aos encontrados por Höhmann, uma vez que foi constatada a preferência e a maior presença do pomerano nas gerações mais velhas.

Em 2013, Savedra e Höhmann publicaram estudo acerca do pomerano no Espírito Santo. As autoras discorrem sobre a revitalização e cooficialização do pomerano em municípios capixabas, assim como apresentam aspectos do Programa de Educação Escolar Pomerana (PROEPO). O projeto nasceu a partir da grande dificuldade encontrada por crianças monolíngues em pomerano de entrar em vida escolar, ambiente onde a língua majoritária, o português, predominava. O PROEPO pretende implementar o ensino do 
pomerano em séries iniciais em escolas das comunidades onde o pomerano é falado, permitindo a integração de crianças à realidade escolar, assim como favorecer a revitalização da língua e da cultura pomeranas nas comunidades em questão.

De acordo com as autoras, o pomerano sempre foi uma língua oral, não possuindo registro escrito. A fim de solucionar esse problema e normatizar a escrita do pomerano, Ismael Tressmann desenvolveu uma escrita para língua pomerana. O Dicionário Enciclopédico Pomerano-Português de Tressman (2006), ou "Pomerisch-Portugijsisch Wöirbauk”, possui 16.000 verbetes com 560 páginas e serviu de apoio para a formulação de materiais utilizados pelo PROEPO. Atualmente, o PROEPO é desenvolvido em cinco municípios capixabas: Laranja da Terra, SMJ, Pancas, Vila Pavão e Domingos Martins, os mesmos onde a língua pomerana é cooficializada.

Atualmente, com a lei das cooficializações e o PROEPO, observa-se uma militância em prol da preservação da língua pomerana por parte da comunidade e também por pesquisadores da área. Recentemente, Hilderson Jacob, Sintia Küster e Lilia Stein, professores preocupados com a manutenção da língua, criaram, com o apoio do Ministério da Cultura, um aplicativo para celular intitulado "Aprenda Pomerano". Aliado às novas tecnologias, os professores acreditam que o aplicativo "contribuirá tanto para ampliação e enriquecimento do vocabulário aos falantes da língua quanto às pessoas que queiram aprender o pomerano" (IPOL, 2016a).

Podemos perceber, a partir das informações apresentadas, a presença inegável da língua pomerana nas comunidades capixabas aqui relatadas. Porém, observa-se também que há aparente perda de vitalidade da língua nas gerações mais novas, justificando a militância em prol da preservação e manutenção do pomerano.

\section{Língua e território: a formação da variedade (neo)autóctone}

Como já visto anteriormente, a chegada dos imigrantes pomeranos ao Brasil foi marcada por muitas adversidades. Era lhes prometido o recebimento de pequenos lotes de terra que eram designados pelas direções das colônias assim que chegassem ao Brasil (RÖLKE, 2016). Apesar de todas as promessas de terras férteis, o que os imigrantes receberam em sua chegada não condizia com o que lhes fora dito. Segundo Bremenkamp (2014):

Na chegada aos seus respectivos lotes, enfim, a decepção foi inexprimível. Todas as promessas feitas a eles eram falsas, a começar pela situação dos lotes, que não passavam de matas fechadas sem nenhuma construção, plantação ou criação de animais. (BREMENKAMP, 2014, p. 64-65). 
O processo de ocupação e povoamento, em que os imigrantes recebiam terras bastante isoladas nas montanhas do Espírito Santo, favoreceu o isolamento das comunidades, que se estabeleciam em locais pouco acessíveis. A esse isolamento, Martinuzzo (2009) chama de "protetor". Segundo o autor, esse isolamento propiciou o fortalecimento e a sobrevivência de traços identitários, como a língua e outras expressões culturais.

De acordo com definição de Santos (2007, p. 13) "território é o fundamento do trabalho, o lugar de moradia, das trocas materiais e espirituais”. A relação dos imigrantes pomeranos com o território era essencial para essa caracterização da nova terra, já que "o território é o lugar possível de se realizarem todas as ações, poderes, forças e fraquezas, onde a história do homem se realiza a partir dos fenômenos de sua existência” (SANTOS, 2007, p. 14).

Para Tacke (2015), a territorialidade desempenha um forte papel na identidade local, pois tanto o indivíduo quanto a comunidade são ligados fortemente pelo espaço geográfico, e essa ligação sociocultural faz parte da construção da identidade individual e coletiva.

Bremenkamp (2014), em sua pesquisa de campo, observou que, atualmente, em Santa Maria de Jetibá, a ligação com a terra é mantida pelos descendentes de pomeranos também nas principais atividades econômicas da região, onde há grande diversidade de produção agrícola.

Bahia (2011) aponta a grande influência das atividades campesinas na chamada Land:

Na língua pomerana, a palavra que designa a unidade familiar como unidade de produção de consumo, juntamente com a propriedade e os animais, objetos e valores que constituem seu modelo de vida, é Land. [...] Na língua portuguesa, temos o uso que fazem da palavra "colônia" que teria o mesmo significado de Land. A palavra "colônia" pode ser usada para se referir à própria terra e seu conjunto, ou à colônia de algum parente ou ainda à região de imigração pomerana no Estado do Espírito Santo. (BAHIA, 2011, p. 47, grifo da autora).

De acordo com a autora, a concepção de família camponesa está estreitamente ligada à ideia de colônia, que caracterizam o campesinato e a etnicidade. Segundo Woortmann:

Nas subjetividades, nos valores e nas crenças, procuro entender, por exemplo, a noção de terra/land não apenas como uma mercadoria, mas também como parte de valores morais centrais na construção das identidades desses camponeses. (WOORTMANN, 1990, apud BAHIA, 2011, p. 34). 
Observa-se que o conceito de Land tratado por Bahia representa muito mais que o território por si, mas também a identidade social e a representação de práticas familiares relacionadas à terra, como a divisão do trabalho, herança, comercialização dos excedentes produzidos, entre outras. A Land, para os pomeranos, como afirma a autora, é sobretudo parte de um valor atrelado à identidade e à etnicidade do povo.

Outra ligação da cultura pomerana com a identidade local é o que se refere à sua língua. Nesse ponto, o marco principal é a cooficialização da língua pomerana, criada em 26 de junho de 2009 com a Lei n 1.136 no Município de Santa Maria de Jetibá. A cooficialização tornou institucional o uso da língua que já era utilizada desde a chegada dos pomeranos.

A cooficialização não somente institucionalizou a grande importância que a língua pomerana tem para a região, comunidade e identidade do povo, mas também vem aprofundar os laços identitários do povo com sua língua e cultura. Concordamos aqui com Tacke (2015), quando o autor declara que uma língua está fortemente vinculada a um território, e, nesse sentido, cria-se um aprofundamento da identidade:

Es geht um die Projektion von Sprache als Identitätssfitende kulturelle Praxis einer Gemeinschaft auf das von ihr besiedelte Gebiet, wobei die Aneignung des Gebietes aus der Gemeinschaft zugleich die Sprache des Gebietes macht. (TACKE, 2015, p. 87-88, tradução nossa). ${ }^{3}$

Com a instauração do Decreto n 7.387 de 9 de dezembro de 2010 (BRASIL, 2010), que implementa o Inventário Nacional da Diversidade Linguística Brasileira, as minorias linguísticas presentes no Brasil foram institucionalmente reconhecidas em âmbito nacional. O INDL também visa a promover a manutenção e a revitalização de minorias linguísticas no Brasil, inventariando e catalogando essas línguas a fim de criar políticas que permitam fortalecer e promover a diversidade linguística nacional.

Para fins de classificação e caracterização, o INDL definiu alguns critérios e procedimentos para que a língua possa ser considerada brasileira: a língua deve ter relevância para a memória e identidade dos grupos que fazem parte da sociedade brasileira há pelo menos 3 gerações, ou 75 anos (MORELLO, 2012).

De acordo com a classificação do INDL, as categorias histórico-sociológicas para a classificação das línguas que constituem o repertório linguístico brasileiro são: indígenas, imigração, comunidades afro-brasileiras, sinais, crioulas e língua portuguesa de variações

\footnotetext{
3 A língua desempenha uma projeção no aprofundamento da identidade como prática cultural de uma comunidade que ocupa uma região, em que a apropriação da região, faz com que, ao mesmo tempo, a língua utilizada por essa comunidade se faça a língua daquela região.
} 
dialetais. Presentes em território brasileiro em diferentes espaços de tempo, algumas dessas categorias, como as de imigração, afro-brasileiras e crioulas, são tratadas por alguns pesquisadores como línguas alóctones, ou seja, línguas não originais do Brasil. A categoria de língua autóctone seria reservada apenas às línguas indígenas, categorizadas como originais do Brasil.

A língua pomerana é uma língua de imigração, que faz parte do repertório linguístico nacional. Está presente no território brasileiro desde a chegada dos primeiros imigrantes pomeranos há cerca de 160 anos e, como já visto anteriormente, mantém um alto grau de vitalidade sendo utilizada por grande parte da população das comunidades de descendentes de pomeranos, como comprovado nos estudos já aqui tratados.

Na verdade, a terminologia de autóctone e alóctone gera bastante discussão, e suas definições devem ser analisadas a partir do tempo que determinada língua e/ou grupo étnico se encontra em um território, como observam Zenker (2011) e Tacke (2015).

Em seus estudos sobre autoctonia, Zenker (2011), numa perspectiva antropológica, apresenta uma revisão do termo "autochtony" com base no que vem sendo estudado acerca da etnicidade. Zenker conclui que a indigeneidade deveria ser entendida como uma versão particular constituinte da autoctonia, e que o termo "autochtony" não deveria ser restritamente ligado à categoria indígena, que até então era a terminologia utilizada para se tratar de autoctonia.

A língua pomerana, pertencente à categoria de língua de imigrantes, recebeu o status de alóctone por muito tempo por ser parte de um povo até então, também, considerado alóctone. Hoje, os habitantes de comunidades pomeranas, por estarem ligados há mais de um século com o território em questão, como em SMJ, se autodenominam autóctones: "Ao passar pelas ruas e avenidas da cidade o visitante encontrará a população autóctone se comunicando em pomerano" (PREFEITURA MUNICIPAL DE SANTA MARIA DE JETIBÁ, 2016b).

Zenker traça uma ligação entre os indivíduos que criam laços com o território e a autoctonia:

Concebida dessa maneira, 'autoctonia' pode ser descrita como uma tríade na qual os seus três elementos: 'individual', 'território' e 'grupo' são casualmente ligados através de interconexões de local de nascimento/ residência, membros de grupos com direitos territoriais [...] e com cultura/ ancestralidade compartilhadas, enquanto assim sendo simultaneamente situados no tempo (ZENKER, 2011.p. 71, tradução nossa). ${ }^{4}$

\footnotetext{
${ }^{4}$ Conceived of in this way, 'autochthony' can be described as a triad in which its three elements - 'individual', 'territory' and 'group' - are causally linked through the interconnections of place of birth/residence, group membership with land(ed) rights $[\ldots]$ and shared culture/descent, while thereby being simultaneously situated in time. (ZENKER, 2011, p. 71).
} 
A cooficialização da língua pomerana em Santa Maria de Jetibá é um exemplo do enraizamento da comunidade pomerana naquele território. Apoiado na Declaração Universal dos Direitos Linguísticos (UNESCO, 1996), Tacke (2015) afirma que, para uma língua e comunidade linguística serem autóctones, estas devem estar historicamente ligadas ao território e, para isso, classifica os graus de autoctonidade da língua.

Figura 2. Graus da autoctonia linguística

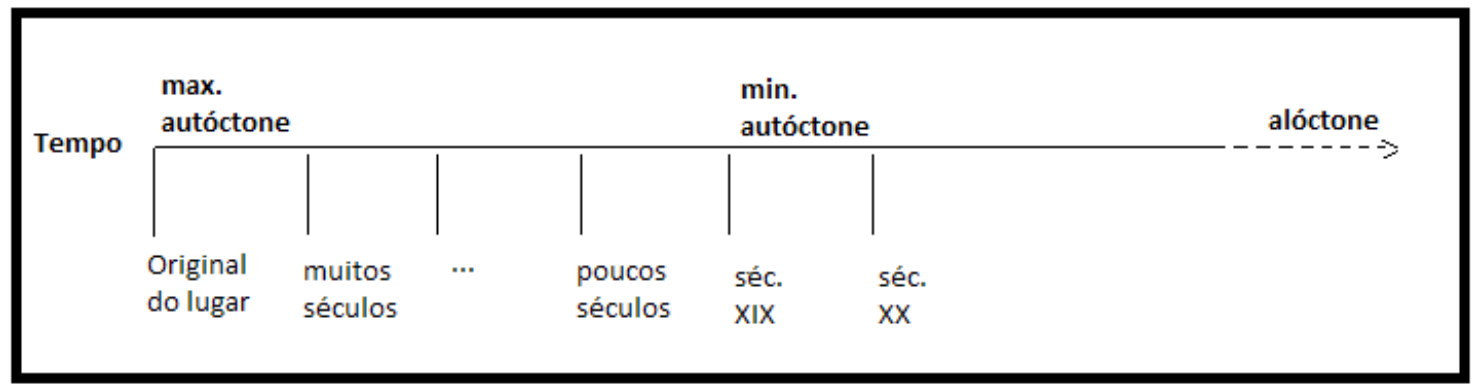

Fonte: Tacke (2015, p. 115, tradução nossa).

De acordo com os graus de autoctonia apresentados por Tacke (2015), observa-se que a língua pomerana, ao se fazer presente desde 1859 em território brasileiro, mais precisamente em SMJ, encaixa-se na classificação de "mínima autóctone", já pertencendo àquela localidade.

Com um alto grau de vitalidade, a língua pomerana, como língua de herança de imigrantes, passou por um processo de cooficialização e faz parte do INDL, tornando-a institucionalmente parte do repertório linguístico brasileiro. Além disso, apoiado Nos estudos de Tacke (2015) e Zenker (2011), permite-se dizer que a língua pomerana é uma língua (neo)autóctone brasileira, pois está estabelecida e enraizada em território nacional desde o século XIX.

\section{Considerações Finais}

O presente trabalho buscou relacionar conceitos e fatos pertinentes à história, imigração, identidade, língua, cultura e territorialidade, a fim de propor uma nova definição para a variedade da língua pomerana falada no Espírito Santo, uma língua (neo)autóctone brasileira, fazendo parte do repertório linguístico do país.

Em toda trajetória dos pomeranos, a língua e os valores relacionados à vida campensina e familiar estiveram presentes e, em território campesino, a língua pomerana resistiu, marcando a importante relação que a língua tem com o trabalho, território e famí- 
lia, valores estreitamente relacionados ao conceito de Land, transmitidos de geração a geração pelos antepassados imigrantes.

Transmitida geracionalmente, esta língua de imigrantes é hoje cooficial no Município de SMJ e em outros municípios do Espírito Santo, sendo parte importante da constituição do Brasil como país plurilíngue e multilíngue. Durante muito tempo línguas minoritárias em espaço brasileiro foram chamadas de alóctones, isto é, línguas não originais do território em questão, sendo reservada também ao pomerano essa classificação. Com a implementação do INDL, a língua pomerana se encaixa no que o Inventário chama de "língua de imigração", ganhando o status de "brasileira". Portanto, afirmamos que a língua pomerana não deve mais ser classificada como língua alóctone.

Além disso, com base nos estudos de Zenker (2011) e Tacke (2015), que revisam o conceito de autoctonia e associam-no com o tempo e a relação que uma língua se estabelece em um território, permite-se dizer que a língua pomerana é uma língua (neo) autóctone por estar presente com um alto grau de vitalidade em SMJ desde o século XIX, data da imigração para a região.

Os estudos sobre as variedades (neo)autóctones brasileiras, em situações similares às da língua pomerana, identificadas e catalogadas pelo INDL, podem ser favoráveis à criação de políticas públicas em âmbito nacional, estadual e municipal, voltadas à proteção, manutenção e revitalização da língua dos povos minoritários brasileiros.

Pensar em um Brasil plurilíngue/multilíngue é pensar na grandeza de um país de muitas línguas, identidades e culturas.

\section{Referências}

Arquivo Público do Estado do Espírito Santo. Arquivo Digital. Imigrantes: Contratos de Colonos. (1859-1860) Disponível em: http://imigrantes.es.gov.br/html/contrato_ colonos.html. Acesso em 17 jan. 2017.

BAHIA, J. O tiro da bruxa: identidade, magia e religião entre os camponesespomeranos do estado do Espírito Santo. Rio de Janeiro: Garamond, 2011.

BRASIL. Decreto n 7.387 , de 9 de dezembro de 2010. Institui o Inventário Nacional da Diversidade Linguística e dá outras providências. Brasília, 2010. Disponível em: https:// www.planalto.gov.br/ccivil_03/_ato2007-2010/2010/decreto/d7387.htm. Acesso em: 9 ago. 2016.

. Lei no 1136 , de 26 de junho de 2009. Dispõe sobre a co-oficialização da língua pomerana no município de Santa Maria de Jetibá, estado do espírito santo. Leis Municipais, SantaMaria deJetibá,26jun.2009.Disponívelem:https://leismunicipais.com.br/a/es/s/ santa-maria-de-jetiba/lei-ordinaria/2009/114/1136/lei-ordinaria.Acessoem:9ago.2016. 
BREMENKAMP, E. S. Análise sociolinguística da manutenção da língua pomerana em Santa Maria de Jetibá, Espírito Santo. 2014. 291 f. Dissertação (Mestrado em Estudos Linguísticos) - Centro de Ciências Humanas e Naturais, Universidade Federal do Espírito Santo, Vitória, 2014.

FOERSTE, E. Língua Pomerana na atualidade: um diálogo sobre patrimônio cultural do povo tradicional pomerano. In: SEIBEL, I. O povo pomerano no Brasil. Santa Cruz do Sul, EDUNISC, 2016.

FRANCESCHETTO, C. Imigrantes no Espírito Santo: base de dados da imigração estrangeira no Espírito Santo nos séculos XIX e XX. Vitória: Arquivo Público do Estado do Espírito Santo, 2014.

HÖHMANN, B. Sprachplanung und Spracherhalt innerhalb einer pommerischen Sprachgemeinschaft. Eine sociolinguistische Studie in Espírito Santo/Brasilien. Frannkfut: Peter Land, 2011. N. B.

.; SAVEDRA, M.M.G; Das Pommerische in Espírito Santo: Ergebnisse und Perspektiven einer soziolinguistischen Studie. Pandaemonium Germanicum, São Paulo, n.18, dez. 2011, p. 283-300. Disponível em: http://www.revistas.usp.br/pg/article/ view/38123/40855

IBGE. Censo Demográfico da população do Espírito Santo 2010. Disponível em: http:// www.ibge.gov.br/home/estatistica/populacao/censo2010/tabelas_pdf/total_ populacao_espirito_santo.pdf Acesso em: 07 set. 2016.

. Estimativas de população dos municípios brasileiros em 2015. Disponível em:

http://www.ibge.gov.br/home/estatistica/populacao/estimativa2015/estimativa_dou. shtm. Acesso em: 7 set. 2016.

. Histórico de Santa Maria de Jetibá. Espírito Santo, 2016. Disponível em: http:// biblioteca.ibge.gov.br/visualizacao/dtbs/espiritosanto/santamariadejetiba.pdf. Acesso em: 06 set. 2016.

IPOL. Professores Pomeranos preocupados com a promoção da língua pomerana ciram o aplicativo aprenda pomerano. Florianópolis, 18 ago. 2016a. Disponível em: http://eipol.org/professores-pomeranos-preocupados-com-a-promocao-da-lingua-pomeranacriam-o-aplicativo-aprenda-pomerano/. Acesso em: 20 jan. 2017.

. Inventário irá promover língua pomerana em nível nacional. Florianópolis, 25 fev. 2016b. Disponível em: http:/ / e-ipol.org/inventario-ira-promover-lingua-pomerana-emnivel-nacional/. Acesso em: 18 jan. 2017.

LESSER, Jeffrey. A invenção da brasilidade: identidade nacional, etnicidade e políticas de imigração. 1. ed. São Paulo: Editora Unesp, 2015.

MARTINUZZO, J. A. Germânicos nas terras do Espírito Santo. Tradução de Helmar Reinhard Rölke. Vitória: Governo do Estado do Espírito Santo, 2009. Edição bilíngue Português e Alemão. 
MORELLO, R. Uma política pública e participativa para as línguas brasileiras : sobre a regulamentação e a implementação do Inventário Nacional da Diversidade Linguística (INDL). Revista Gragoatá, Niterói, v. 32, n. 17, p. 32-42. $1^{\circ}$ semestre. 2012.

- A cooficialização da língua pomerana no Espírito Santo e no Rio Grande do Sul. In: MORELLO. R. (Org.). Leis e línguas no Brasil. O processo da cooficaliazação e suas potencialidades, 2015. p. 43-54.

PREFEITURA MUNICIPALDE SANTA MARIADEJETIBÁ. Portal.2016a. Disponível em: http://www.pmsmj.es.gov.br/portal/. Acesso em : 18 de janeiro de 2016.

PREFEITURA MUNICIPAL DE SANTA MARIA DE JETIBÁ. Município. 2016b. Disponível em: http://www.pmsmj.es.gov.br/portal/o-municipio/. Acesso em : 18 de janeiro de 2016.

RÖLKE, H. R. Descobrindo raízes: aspectos geográficos e culturais da Pomerânia. Vitória: UFES. Secretaria de Produção e Difusão Cultural, 1996.

. Raízes da imigração alemã. História e cultura alemã no Espírito Santo. Vitória: Arquivo Público do Estado do Espírito Santo, 2016.

SANTOS, M. O dinheiro e o território. In: SANTOS, Milton (Org.). Território, territórios: ensaios sobre o ordenamento territorial. Rio de Janeiro: Lamparina, 2007.

SAVEDRA, M. M. G.; HÖHMANN, B. Das plurizentrische Deutsch in Brasilien und die regionale Koofizialisierung eines ostniederdeutschen Dialekts. In: SCHEIDERWIEJOWSKI, K.; KELLERMEIER-REHBEIN,B.; HASELHUBER,J. (Orgs.). Vielfalt, Variation und Stellung der deutschen Sprache. 1. ed. Berlin: De Gruyter Mouton, 2013, v.1, p. 411-426.

SEIBEL, I. Os pomeranos brasileiros” In: O povo pomerano no Brasil. Santa Cruz do Sul, EDUNISC, 2016.

SEYFERTH, G. “Colonização, imigração e a questão racial no Brasil”. Revista USP, n. 53, p. 117-149, março/maio 2002.

SKIDMORE, T. E. Racial ideas and social policy in Brazil, 1870-1940. In: GRAHAM, R. (Ed.). The idea of race in Latin America, 1870-1940. Austin, University of Texas, 1997. p. 7-36.

TACKE, F. Sprache und Raum in der Romania. Berlin: De Gruyter, 2015.

TRESSMANN, I. Da sala de estar à sala de baile: estudo etnolingüístico de comunidades camponesas pomeranas do estado do Espírito Santo. 2005. 335f. Tese (Doutorado em Linguística) - Programa de Pós-Graduação em Letras, Universidade Federal do Rio de Janeiro, Rio de Janeiro, 2005.

. Dicionário enciclopédico pomerano-português. Pomerisch Portugijsisch Wöirbauk. Santa Maria de Jetibá: Secretaria de Educação, 2006.

. Pomerano: Uma língua baixo-saxônica. Educação, Cultura, Sociedade. Revista da Farese, v. 1. Santa Maria de Jetibá. p. 10- 21, 2008. 
UNESCO. Declaração Universal dos Direitos Linguísticos. Barcelona, jun.1996. Disponível em: http://www.dhnet.org.br/direitos/deconu/a_pdf/dec_universal_direitos linguisticos.pdf. Acesso em: 15 jan. 2017.

Language Vitality and Endangerment. Paris, mar. 2003. Disponível em: http:/ / www.unesco.org/culture/ich/doc/src/00120-EN.pdf. Acesso em: 21 jan. 2017.

ZENKER, O. Autochthony, ethnicity, indigeneity and nationalism: time-honouring and state-oriented modes of rooting individual-territory-group triads in a globalizing world. Critique of Anthropology, v. 31, p. 63-81, 2011.

Data de submissão: 22/01/2017

Data de aceite: $11 / 04 / 2017$ 